University of Wollongong

Research Online

Faculty of Social Sciences - Papers (Archive) Faculty of Arts, Social Sciences \& Humanities

2011

Relevance of the International Prognostic Index in the Rituximab era

Kevin Tay

National Cancer Centre Singapore

David Tai

National Cancer Centre Singapore

Miriam Tao

National Cancer Centre Singapore

Richard Quek

National Cancer Centre Singapore

Tam C. Ha

University of Wollongong, tamha@uow.edu.au

See next page for additional authors

Follow this and additional works at: https://ro.uow.edu.au/sspapers

Part of the Education Commons, and the Social and Behavioral Sciences Commons

Research Online is the open access institutional repository for the University of Wollongong. For further information contact the UOW Library: research-pubs@uow.edu.au 


\title{
Relevance of the International Prognostic Index in the Rituximab era
}

\author{
Abstract \\ Letter to the editor \\ Keywords \\ era, rituximab, prognostic, relevance, index, international \\ Disciplines \\ Education | Social and Behavioral Sciences \\ Publication Details \\ Tay, K., Tai, D., Tao, M., Quek, R., Ha, T. C. \& Lim, S. T. (2011). Relevance of the International Prognostic \\ Index in the Rituximab era. Journal of Clinical Oncology, 29 (1), e14. \\ Authors \\ Kevin Tay, David Tai, Miriam Tao, Richard Quek, Tam C. Ha, and Soon Thye Lim
}




\section{Relevance of the International Prognostic Index in the Rituximab Era}

To THE EDITOR: We read with interest this meta-anaylsis by Ziepert et al ${ }^{1}$ involving 1,062 patients with diffuse large B-cell lymphoma accrued from three prospective phase II/III trials: MinT (Mab-Thera International Trial), RICOVER-60 (cyclophosphamide, doxorubicin, vincristine, and prednisone plus rituximab [R-CHOP] for patients older than age 60 years), and MegaCHOEP (dose-escalated regimen of cyclophosphamide, doxorubicin, vincristine, etoposide, and prednisone) trials..$^{2-4}$ The authors affirms the prognostic relevance of the International Prognostic Index (IPI) score for all three end points of progression-free survival, event-free survival, and overall survival. Thus, they concluded that IPI should remain the major tool for risk stratification for patients with diffuse large B-cell lymphoma in the era of rituximab.

While we agree with Ziepert et $\mathrm{al}^{1}$ that the IPI will remain an important prognostic tool until a new scoring system or novel prognostic markers are validated, we would like to address several issues raised in this article. Firstly, it should be noted that different chemotherapy regimens were used in the three trials from which data was collected. Patients treated with MegaCHOEP were given high-dose chemotherapy that was used as a mobilization regimen for autologous stem-cell transplantation. ${ }^{4}$ Likewise, it is unclear if the efficacy of R-CHOP14 which was studied in the RICOVER-60 trial, is similar to R-CHOP21 which was used in approximately $50 \%$ of patients in the MinT trial. ${ }^{2,3}$ Ziepert et al must have believed that these regimens are of different efficacies and thus applied them to different prognostic groups as defined by the IPI. ${ }^{5}$ Prognostic factors are dependent on the efficacy of the regimen used. ${ }^{6,7}$ However, in this analysis, the patients were combined and analyzed together as though there are no differences in the efficacies of the regimens used and prior stratification unimportant. It would be helpful for Ziepert et al to clarify the statistical validity of combining patients with different prognostic risks treated with separate regimens with potentially varying efficacy in the same analysis.

Ziepert et al ${ }^{1}$ also highlighted that their data set contained an overrepresentation of patients with good risk factors. Conversely, we would like to point out that there is an under-representation of young high-risk patients in their data set. Only 55 young patients with two or more risk factors, out of a total number of 1,062 patients were included in the analysis. In fact, almost $60 \%$ of the patients in the analysis were obtained from the RICOVER-60 trial. Thus, the findings of this analysis could potentially be a reflection of the RICOVER- 60 trial.

Furthermore, it is conceivable that with the introduction of rituximab, previously identified prognostic factors may no longer be relevant. Thus, simply adopting an index that comprises of prognostic factors derived from the prerituximab era may be less applicable. Using the IPI in this analysis, the authors will not be able to identify any subgroup with an overall survival less than $59 \%$. In addition, the multivariate analysis reported in this study, only demonstrated four out of the five IPI factors retained their prognostic relevance. It might be more useful to use these factors identified in the rituximab era to construct a new prognostic model.

We also retrospectively compared the prognostic factors of $320 \mathrm{pa}-$ tients treated with R-CHOP at our institution from 2000 to 2008. While factors such as performance status, stage, lactate dehydrogenase level, age, B symptoms, bone marrow involvement, and more than one extra-nodal site of involvement were significant prognostic factors on univariate analysis, only performance status and bone marrow involvement remained as independent prognostic factors on multivariate analysis. In our analysis, although IPI was still predictive of survival, it could only identify three risk groups of patients and could no longer identify patients with less than $60 \%$ chance of survival, consistent with the findings of Ziepert et al ${ }^{1}$ as well as with an earlier report by Sehn et al. ${ }^{8}$

Therefore, rather than relying on the IPI alone, it would be useful to identify new clinical and molecular factors that can better identify patients at high risk of treatment failure in the rituximab era. The relevance of previously identified risk factors should also be individually reconfirmed in the rituximab era so that the prognostic index is more robust and relevant.

\section{Kevin Tay, David Tai, Miriam Tao, Richard Quek, Tam-Cam Ha, and Soon-Thye Lim \\ National Cancer Center Singapore, Singapore}

\section{AUTHORS' DISCLOSURES OF POTENTIAL CONFLICTS OF INTEREST}

The author(s) indicated no potential conflicts of interest.

\section{REFERENCES}

1. Ziepert M, Hasenclever D, Kuhnt E, et al: Standard International Prognostic Index remains a valid predictor of outcome for patients with aggressive CD20+ B-cell lymphoma in the rituximab era. J Clin Oncol 28:2373-2380, 2010

2. Pfreundschuh M, Trumper L, Osterborg A, et al: CHOP-like chemotherapy plus rituximab versus $\mathrm{CHOP}$-like chemotherapy alone in young patients with good-prognosis diffuse large-B-cell lymphoma: A randomised controlled trial by the MabThera International Trial (MInT) Group. Lancet Oncol 7:379-391, 2006

3. Pfreundschuh $M$, Schubert J, Ziepert $M$, et al: Six versus eight cycles of bi-weekly CHOP-14 with or without rituximab in elderly patients with aggressive CD20+ B-cell lymphomas: A randomised controlled trial (RICOVER-60). Lancet Oncol 9:105-116, 2008

4. Glass B, Kloess M, Bentz M, et al: Dose-escalated CHOP plus etoposide (MegaCHOEP) followed by repeated stem cell transplantation for primary treatment of aggressive high-risk non-Hodgkin lymphoma. Blood 107:3058-3064, 2006

5. Anonymous: A predictive model for aggressive non-Hodgkin's lymphoma. The International Non-Hodgkin's Lymphoma Prognostic Factors Project. N Engl J Med 329:987-994, 1993

6. Pfreundschuh $M$, Trumper $L$, Kloess $M$, et al: Two-weekly or 3-weekly CHOP chemotherapy with or without etoposide for the treatment of elderly patients with aggressive lymphomas: Results of the NHL-B2 trial of the DSHNHL. Blood 104:634-641, 2004

7. Pfreundschuh $M$, Trumper $L$, Kloess $M$, et al: Two-weekly or 3-weekly $\mathrm{CHOP}$ chemotherapy with or without etoposide for the treatment of young patients with good-prognosis (normal LDH) aggressive lymphomas: Results of the NHL-B1 trial of the DSHNHL. Blood 104:626-633, 2004

8. Sehn LH, Berry B, Chhanabhai M, et al: The revised International Prognostic Index (R-IPI) is a better predictor of outcome than the standard IPI for patients with diffuse large B-cell lymphoma treated with R-CHOP. Blood 109:1857-1861, 2007

DOI: $10.1200 / J C O .2010 .31 .7677$; published online ahead of print at www.jco.org on November 29, 2010 